\title{
Collaborative facilitation of mental health of disaster responders
}

Preparation to reduce stressors and respond to stress reactions before and around a response to a natural disaster can facilitate greater mental wellbeing after the disaster. To protect their mental health, the individual disaster responders' actions are just as important as the organisational support. A review by Maki Umeda and collaborators
at University of Hyogo (Japan), Kobe University (Japan) and Syarif at University of Hyogo (Japan), Kobe University (Japan) and Syarif interventions that can be undertaken by individual disaster responders and their organisations through their responding journey. Pre-activity the focus is on planning to prevent extreme stress; during the activity, identifying and responding to stressors takes precedence; and postactivity, it is important to return to normal routines.

\section{The World Health Organization (WHO) states disasters can (i)} chemical spills and nuclear accidents. Regardless of the type of disaster, there are always impacts on health.

The role of the United Nations Office for Disaster Risk Reduction (UNDRR) and review of the Sendei Fram for Disaster Risk Reduction. They define disaster risk through its impact, potential loss of life or iniury destruction, or damage to assets, and

determine where disasters are likely to occur, which could be to a system, society, or a community in a specific period. The level of risk is calculated through the measurement of hazard, exposure, vulnerability, and capacity NATURAL DISASTERS Natural disasters are times of crisis due to events occurring in the physical environment that have the of property. They include earthquakes, droughts, floods, tsunamis, volcanic eruptions or even pandemics such as the COVID-19 pandemic we currently (1) $\begin{gathered}\text { experience. The frequency } \\ \text { and severity of natural } \\ \text { disasters is increasing }\end{gathered}$ due to several risk factors; however, the main culprits are global urbanisation, ( Unmitigated climate change. The health mpact is compounded by increasingly werldwide, such as an abing population.

\section{STRATEGIC RESPONSE}

Escalation of natural disasters and pandemics has increased the WHO concerns over their impact and the essential health interventions
required. In 2016, in response to the Sendai Framework for Disaster Risk Reduction 2015-2030, the WHO developed their Thematic Platform for Health Emergency and Disaster Risk Management (EDRM) Research Network (TPRN). The network identified five major areas for Healt EDRM: health data management, psychosocial management, community development, and research morce and ethics.

TPRN academics, policy developers and clinicians are working through the research questions related to each of these areas. Maki Umeda from the Research Institute of Nursing Care for People and Community at University of Hyogo in Japan and her colleagues Sonoe Mashino (University of Hyogo, Japan), Rie Chiba (Kobe University, Japan), Mie Sasaki (University of Hyogo, Japan) and Eni Nuraini Agustini (Syarif Hidayatullah State Islamic University, Indonesia) are focused on psychosocia management in relation to the heal workforce development. They found there was little obvious scientific
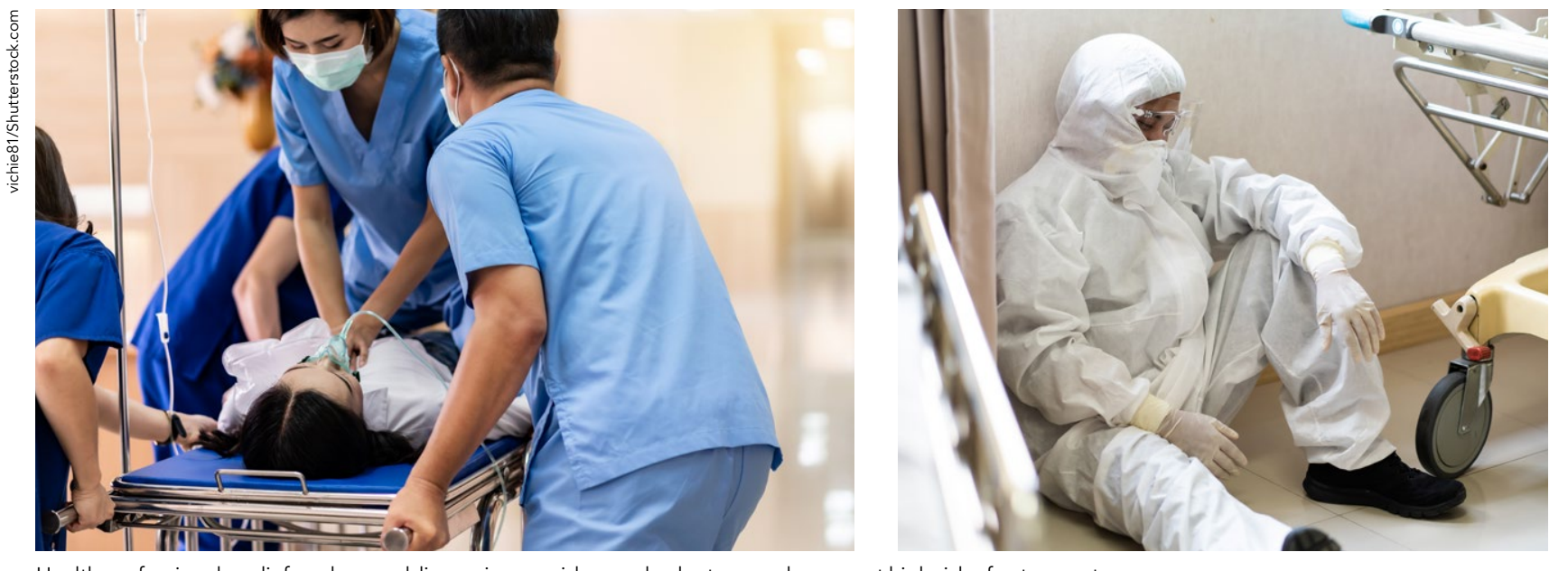

reduce psychological stress or maintain mental health for disaster responders.

IMPACT ON DISASTER

\section{RESPONDERS}

In responding to disasters, health

perice provide re

are at high risk of extreme stress. This

occurs through exposure to traumatic

events, a high level of work demands

with limited resources, working with

highly stressed populations in critical

moments, and separation from their

social support networks such as home

family and friends.

The trauma and psychological impact on survivors of natural disasters is recognised in academic literature, but there is an increasing concern for disaster responders. This is now becoming a major focus of disaster problems after responding to disssters is believed to be as high as $60 \%$. The psychological disorders experienced include increased anxiety, depression, stress-related disorders, and alcohol and substance abuse. These can

substantially decrease quality of life and negatively affect physical wellbeing and social functioning

\section{THE REVIEW}

Dr Umeda and her colleagues therefor undertook a systematic review of the evidence avallable to establis which psychosocial interventions were most efficacious. The research team examined all scientific papers, agency reports, the manuals of aid published in English or Japanese to identify field-based knowledge and practices for psychosocial support. actions that could protect and improve the mental health of disaster responders. They then identified thre goals: to understand stressors and make them manageable, to reduce stressors and prevent chronically stressful situations, and to respond to was overwhelming

Umeda and her colleagues' review highlighted the need to provide

Escalation of natural disasters and pandemics has increased the WHO's concerns over their impact and the essential health interventions required.

psychological support to disaster responders at each stage of their journey. Alongside organisational support and health management individuals' stress management working to be enhanced and team also identified the importance external resources.

The disaster responder's journey involves the pre-activity phase or preparation phase, the activity or disaster respons phase and the post-activity phase the responder requires different harmonious supportand perst but of coordination and accessing
PRE-ACTIVITY PHASE In the pre-activity phase, the for the role they are underly prepare for the rol they are crestion abit they duties and the area of operation. Once assess their readiness to join the disaster response team. Once they have gained this insight, they need to discuss their circumstances with their close family members. If there are any concerns within or regarding their family, these should be solved before departing.

physical and and seek to be aware of personal indicators of stress, fatigue, and crisis. In addition, they should learn stressmanagement skills and develop their own self-care plan.

Prior to enrolment, organisations need to carefully consider who should be part of the response team and ensure each person has a clear understanding of their role. Alongside identifying roles, organisations need to develop This includes an effective process This includes an effective process to address responders' experiences
of trauma. It also needs to facilitate hey have reached an understanding 


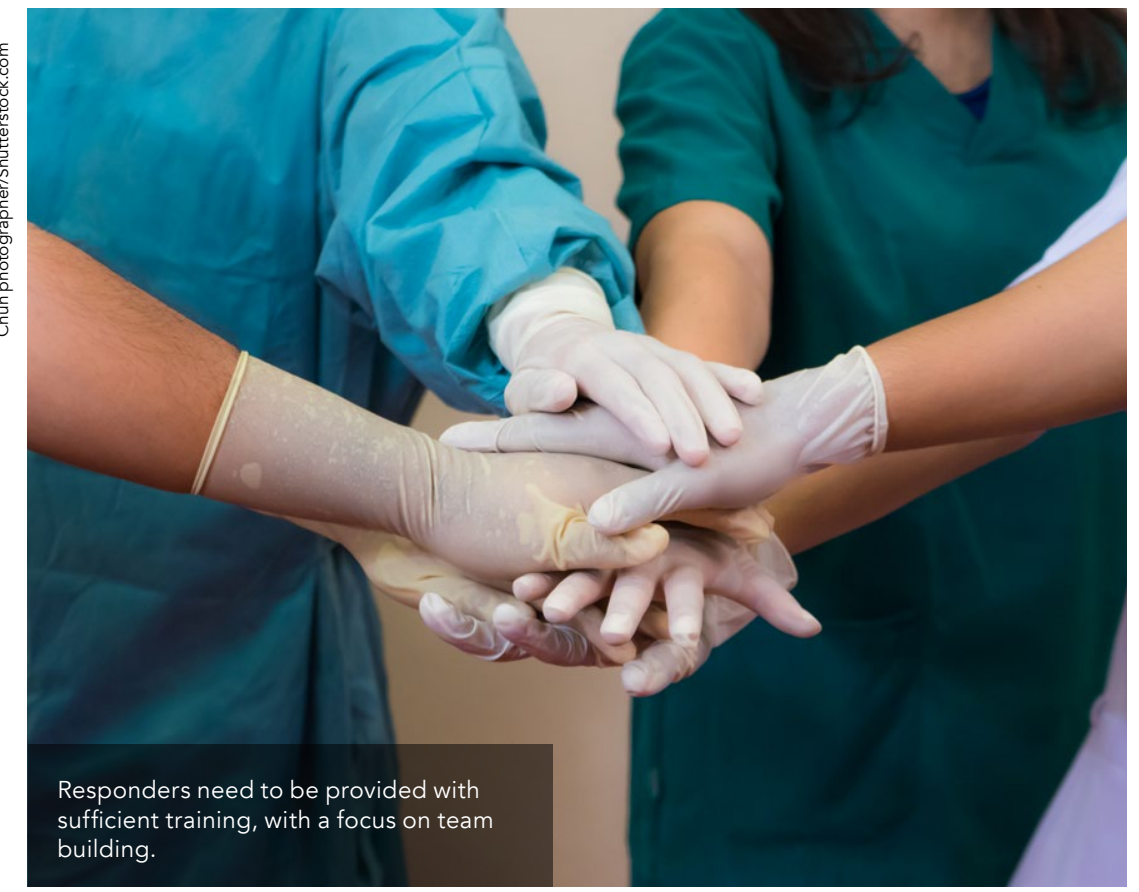

Umeda and her colleagues' review

highlighted the need to provide psychological support to disaster responders at each stage of their journey. communication with responders' families during deployment.

Once responders have been recruited, they need to be provided with sufficien training with a focus on team building Training should entall psychological first aid, the ability to anticipate and montor personal stess

\section{ACTIVITY PHASE}

In response to a disaster, both the individual and the organisation need to identify and monitor stressors and their impact to provide a platform for protecting mental health

At a cognitive level, responders need to re-conceptualise how they make sense of their experiences to allow them to take a step back and be as objective as possible. This will enhance their coping ability. Staying connected to their family can also provide emotional support an

More practically, responders should ake care of their physical and menta

Once stress becomes unavoid adjusted and if the love of seems overwhelming, mental-health professionals could be accessed. A decision may need to be taken as to with work or resign their duties.

AFTER THE DISASTER RESPONSE There may be a need to reappraise experiences and feelings remembered from the activities. Individuals will need to move from 'disaster-response mode' to 'routine mode' - an effective way of maintaining mental health.

Responders need to be encouraged to take time off from work in order to promote recovery from physical and psychological fatigue. Those who suffer from stress may need to rest for considerable amount of time. It is with others.

Organisations need to provide a clear They need to recognise the respod. work as an essential contribution the organisational goals, and to demonstrate their appreciation to Organisations will need to provide opportunities for reappraisal in the form of workshops, seminars, etc., facilitating getting back to usual routines, on-going information provision on self-care, sharing of experiences, and long-term follow-up.

Responders should be enabled to rest before going back to routine work, an if there is on man need adjustment there is ongoing stress. The use of professionats may be required.

\section{CONCLUSION}

After their review of the literature Umeda and her colleagues found that it was equally important for disaster responders and the organisations they work for to 'be aware', 'prevent', and 'respond':

- Be aware of roles, stressors, coping strategies, individual responses etc. - Prevent mental health problems from occurring by putting effective operational strategies in place, with a Respond when stressors are identified resources such as peer support, cources suth as per support, professional support. promote responder's mental health. focus on team working and education.

\section{Behind the Research

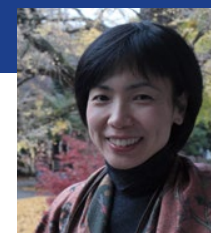 \\ Dr Maki \\ Dr Maki \\ E: maki_umedae \\ cans.u-hyogo.ac.jp

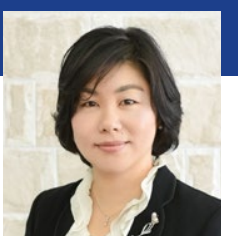 \\ Dr Sonoe Mashino \\ E: sonoe_mashino@ \\ $\frac{\text { cnas.u-hyogo.ac.jp }}{\mathrm{T}:+81 \text { 78-925-9658 }}$

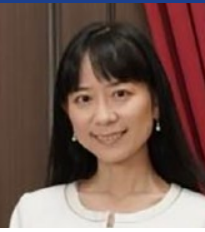 \\ Dr Rie \\ Chiba \\ E: crie-tky@umin. \\ T: +81 ac.jp $78-796-4575$ \\ Dr Mie \\ Sasaki \\ E: mie-sasaki@ \\ T: $\underset{\text { umin.ac.jp }}{\text { un } 78-925-9605}$ \\ N. \\ Dr Eni \\ Nuraini Agustini E: eni.nuraini@uinjkt. T: +62 ac.id $812-8595-470$ \\ W: https://www.u-hyogo.ac.jp/careken/ W: https://www.facebook.com/RINCPC}

\section{Research Objectives}

The research group develops psychosocial support strategies to improve the mental health of disaster responders.

\section{Detail}

Maki Umeda

13-71, Kitaoji-cho, Akashi,

Hyogo 673-8588, Japan

Bio

Maki Umeda, RN, PHN, MPH, PhD is in mental health, and serves as a

Professor of Global Health Nursing at Research Institute of Nursing Care for Hyogo, Japan. She has been involy of in mental health research in Fukushim after the Great East Japan Earthquake.

Sonoe Mashino, RN, PHN, PhD is the Executive Director, PHN, PhD it

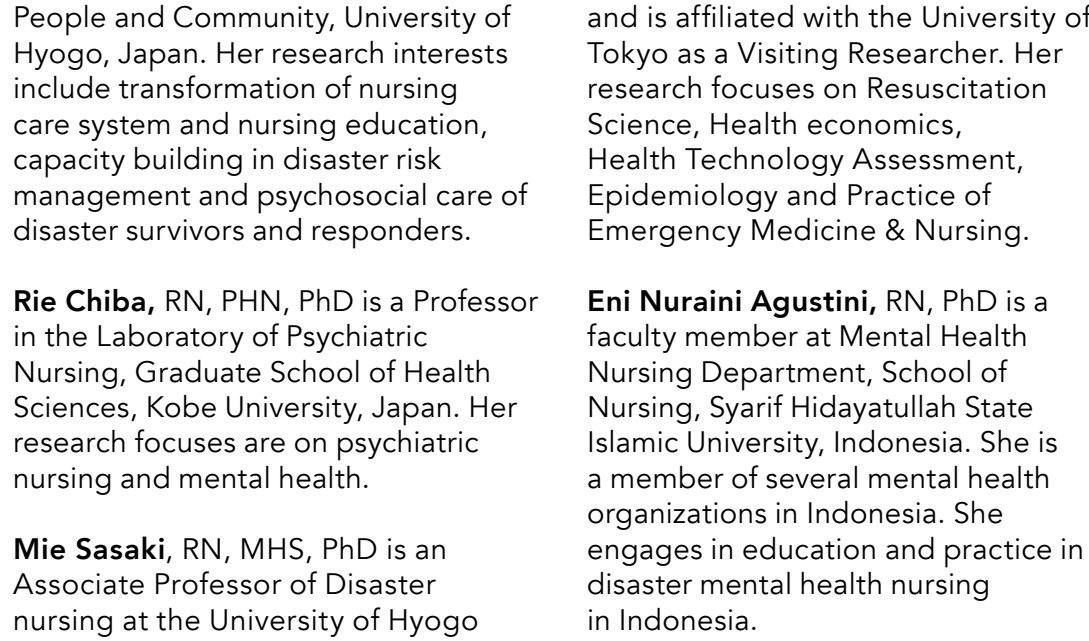

\section{References}

- Umeda, M., Chiba, R., Sasaki, M., Agustini, E., and Support for Disaster Responders: Qualitative Synthesis with Recommended Actions for Protecting and Promoting the Mental Health of Responders. Int.J. Jnviron. Res. Public ijerph170620

Egawa, S., Sasaki, H., Suppasri, A., Tomita, H., Imamura, F. et al. (2020). WHO Guidance on Research Methods for Guidance on Research Methods for Health and Disaster Risk Management. Available at: https://lextranet.who.int kobe_centre/sites/default/files/pdt/WHO\%20Guidance Research\%20Methods Health-EDRM_1.3.pd (2019). WHO The Disaster Risk Management Research Network (TPRN): Report of the Kobe Expert Meeting. Int. J. Environ. Res. Public Health, 16, 1232. Available at: https://doi.org/10.3390/

\section{Personal Response}

What inspired you to conduct this research?

II In the aftermath of the Great East Earthquake, I observed the public servants in affected areas working restlessly although they themselves were affected
by the disaster. It was heartbreaking to see that the irritation and anger of survivors, who were also in critical moments, often had to be directed to these workers. This experience taught me disaster responders need to be protected physically, psychologically, and socially to
help others in affected areas. 